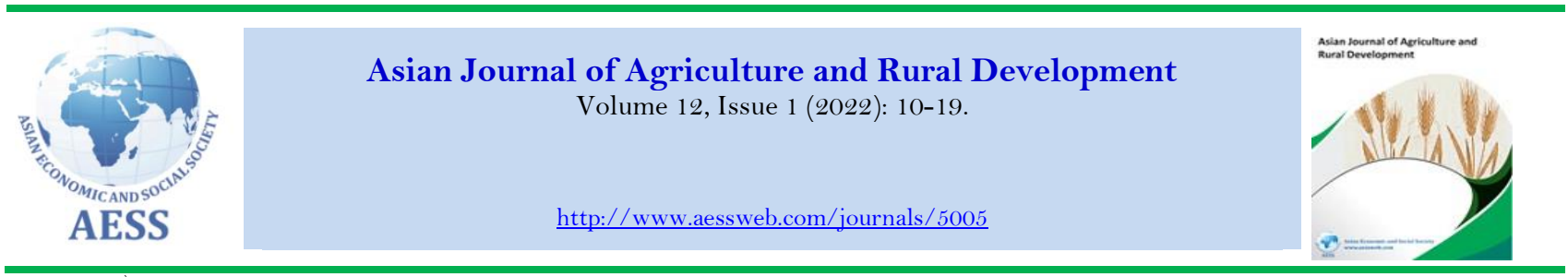

\title{
SEASONAL DISTRIBUTION, ANTIMICROBIAL ACTIVITY, AND RISK FACTORS ASSOCIATED WITH THE INCIDENCE OF STAPHYLOCOCCUS SPECIES IN BOVINE MILK FROM A DAIRY FARM IN EASTERN CAPE, SOUTH AFRICA
}

\author{
Idamokoro Emrobowansan \\ Monday $^{\mathrm{a}, \mathrm{b}}$ i \\ iD Yiseyon Sunday Hosu ${ }^{\mathrm{a}, \mathrm{b}}$
}

\section{Article History}

Received: 30 April 2021

Revised: 14 December 2021

Accepted: 4 January 2022

Published: 28 January 2022

\section{Keywords}

Milk

CNS

Antibiotics

Multiple drug resistance.

\begin{abstract}
${ }^{a}$ Small-Scale Agribusiness and Rural Non-farm Enterprise, Niche Area, Walter Sisulu University, Mthatha, South Africa.

${ }^{b}$ Faculty of Commerce and Administration, Department of Economics and Business Sciences,
\end{abstract} Walter Sisulu University, Mthatha, South Africa.

\section{ه mondayidamokoro@gmail.com(Corresponding author)}

Contribution/Originality: The paper's primary contribution is finding that there was high incident rate and multiple drug resistance of Staphylococcus species against selected antibiotics such as penicillin that is used in dairy farms.

DOI: $10.18488 / 5005 . v 12 \mathrm{i} 1.4412$

$\operatorname{ISSN}(\mathrm{P}):$ 2304-1455/ ISSN(E): 2224-4433

How to cite: Idamokoro Emrobowansan Monday --- Yiseyon Sunday Hosu (2022). Seasonal Distribution, Antimicrobial Activity, and Risk Factors Associated with the Incidence of Staphylococcus Species in Bovine Milk from

a Dairy Farm in Eastern Cape, South Africa. Asian Journal of Agriculture and Rural Development, 12(1), 10-19. 10.18488/5005.v12i1.4412

(C) 2022 Asian Economic and Social Society. All rights reserved.

\section{INTRODUCTION}

One major disease that increases the cost of production on dairy farms is mastitis (Dufour et al., 2012). The welfare of dairy cows can be negatively impacted due to a high incidence of mastitis in their milk (Hogeveen, Huijps, \& Lam, 2011). Farmers incur a significant amount of economic loss as a result of mastitis infection in cows which leads to a 
reduction in milk yield (Ampe, Goethals, Laevens, \& Duchateau, 2012; Halasa et al., 2009). Thousands of bacteria have been reported to cause mastitis in dairy animals (Batavani, Asri, \& Naebzadeh, 2007). Of the numerous bacteria linked with mastitis infections in dairy farms, Staphylococcus species stands out (Sawant, Gillespie, \& Oliver, 2009; Taponen, Simojoki, Haveri, Larsen, \& Pyörälä, 2006). This species is largely divided into two groups, namely coagulase-negative staphylococci (CNS) (e.g., Staphylococcus epidermidis, Staphylococcus sciuri, Staphylococcus haemolyticus, Staphylococcus hyicus) and coagulase-positive staphylococci (CPS) (e.g., Staphylococcus aureus). The CNS group consists of a class of species that differ in the way they cause mastitis infection in animals (Waller, Aspán, Nyman, Persson, \& Andersson, 2011; Zhang \& Maddox, 2000).

Lately, CNS has become more significant as a bovine-mastitis-causing organism (Simojoki, Salomäki, Taponen, Iivanainen, \& Pyörälä, 2011). Isolates of CNS species are habitually identified in bovine milk as a cause of intramammary infection (Tenhagen, Köster, Wallmann, \& Heuwieser, 2006). They cause both clinical and subclinical mastitis in cattle (Supré et al., 2011), though clinical mastitis caused by CNS species may be placid in some cases (Taponen \& Pyörälä, 2009). Common CNS species isolated from bovine mastitis include Staphylococcus chromogenes, Staphylococcus xylosus, Staphylococcus epidermidis, Staphylococcus sciuri, and Staphylococcus haemolyticus (Kot et al., 2012; Tenhagen et al., 2006). Other CNS species (e.g., Staphylococcus saprophyticus, Staphylococcus hominis, Staphylococcus warneri, Staphylococcus capitis) causing bovine mastitis have been well documented (Sampimon, Lam, Mevius, Schukken, \& Zadoks, 2011).

Several nations have identified CNS species to be a preponderant agent causing mastitis infections in cows when compared to other mastitis-causing agents (Piepers et al., 2007; Pitkälä, Haveri, Pyörälä, Myllys, \& Honkanen-Buzalski, 2004; Pyörälä \& Taponen, 2009). However, the prevalence of CNS varies from country to country (Taponen \& Pyörälä, 2009). Additional factors like farm area and environment (Piessens et al., 2012), farm management systems (Ayano, Hiriko, Simyalew, \& Yohannes, 2013), and season may influence the incidence of the bacterial species on a farm.

A survey carried out in South Africa, for instance, indicated that CNS was a major cause of both clinical and subclinical mastitis infection (Petzer, Karzis, Watermeyer, Van der Schans, \& Van Reenen, 2009). Various factors were linked to the CNS spread among cow herds in South Africa, including large herd size, meager milking practice, inefficient milking machine maintenance, an influx of new stock of cows, and high milk yield by cows. Most studies reported CNS as a group and not at their species level. Various CNS species differ in their ability to cause infection in cows due to their different virulence (Simojoki et al., 2011). The distribution of CNS also varies in different regions of a particular country (Koivula, Pitkälä, Pyörälä, \& Mäntysaari, 2007; Shekhan, Al-Rodhan, \& AL-Janabi, 2011). Influences such as time of the year and parity and stage of lactation have also been indicated as factors determining the distribution of CNS pathogens in various regions within a country (Gröhn et al., 2004; Koivula et al., 2007; Taponen, Koort, Björkroth, Saloniemi, \& Pyörälä, 2007). Thus, the need to identify CNS at the species level is important for effective mastitis control programs (Supré et al., 2011).

There is increased use of antimicrobials to treat mastitis on many farms (Walther, Rossano, Thomann, \& Perreten, 2008) during lactation and in the dry cow stage treatment (Sawant, Sordillo, \& Jayarao, 2005). However, several Staphylococcus species are resistant to antimicrobials (Sampimon et al., 2011). According to the World Health Organization (2000), the increase of bacterial resistance to antibiotics is worrisome.

Dairy farmers in the Eastern Cape Province of South Africa are aware of Staphylococcus aureus as a cause of mastitis, but not the other species. Farmers acknowledge mastitis as one of the greatest challenges they face on their dairy farms. This study investigates the incidence of Staphylococcus species and the in-vitro antimicrobial sensitivity pattern of these species in cows' milk collected over a nine-month period in 2012 from a dairy farm located in the Eastern Cape of South Africa.

\section{MATERIAL AND METHODS}

\subsection{Study Site Description}

The study was conducted on a dairy farm located in Middle Drift of Raymond Mhalaba municipality in Eastern Cape Province of South Africa. The farm was on 250 hectares of land with 600 milking cows, producing 3,000-3,500 liters of milk per day. The average annual rainfall of the farm is $591 \mathrm{~mm}$ per annum. Rainfall between May and September is less than $25 \mathrm{~mm}$ per annum and 50-100 mm between November and March. The topography of the farmland is flat with a gentle slope, and it has an altitude of $420-470 \mathrm{~m}$. In July, the average daily temperature is between $28.2^{\circ} \mathrm{C}$ and $30.0^{\circ} \mathrm{C}$.

\subsection{Animal Description}

Three dairy breeds (Friesian, Jersey, and their crosses (Friesian x Jersey) were kept for milk production. Milk samples were collected from each breed for bacterial examination during the nine-month study. Each cow used for milk sampling was identified based on their colors, information from the farmers, and ear-tags. Data including lactation stage and parity of the cows were taken at each sampling.

\subsection{Milk Sample Collection}

Composite raw milk samples were collected from selected cows in a $10 \mathrm{ml}$ sterile sampling bottle after pre-milking tests (strip cup test and California mastitis test) were carried out on the cows. Milk sampling bottles were then labeled appropriately and immediately stored in a cooler box with ice before they were transported to the laboratory for bacterial culture analysis. Milk samples were collected between March and November 2012, which accounted for three different sampling periods (hot-wet, cold-dry, and hot-dry), and this was done twice for each sampling period. 


\subsection{Culturing of Milk Samples in Mannitol Salt Agar}

The milk samples were aseptically streaked in a freshly prepared Mannitol salt agar within 24-48 hours of collection from the farm and incubated at $37^{\circ} \mathrm{C}$ for $24-48$ hours. Isolates that gave a yellow color when fermented on Mannitol salt agar were sub-cultured in nutrient agar.

\subsection{Sub-Culturing of Milk Samples in Nutrient Agar}

Presumed isolates that were positive in Mannitol salt agar were sub-cultured again in a freshly prepared nutrient agar (within 24 hours) and then placed in an incubator for 24-48 hours. This was done to get a pure colony of the bacteria isolate.

\subsection{Gram's Staining Test}

All cultures of presumed Staphylococcus species were subjected to gram's stain. A few colonies of pure cultured isolates were aseptically picked from the nutrient agar and smeared on a sterile glass slide. The smeared culture was heat fixed. Crystal violet (0.5\%) was added to the smear and left for 1 minute. Water was used to wash the stain from the slide. A sufficient solution of iodine was added to the smear and left for 1 minute. Water was used to wash the stain. Ethanol (95\%) was used to rinse the stain from the slide. Safrani solution was finally added to the smear for 2 minutes before being washed with water. The smear was allowed to dry for a few minutes before being viewed under a light microscope to determine the colony structure of the bacteria species. The smear of each bacteria species was viewed under the 10x, 40x, and 100x magnification. Gram's stain smears that were positive displayed a grape-like cluster shape with deep blue to purple color.

\subsection{Oxidase Test}

A few colonies of isolates presumed to be Staphylococcus species were picked from the nutrient agar aseptically using a sterile loop and placed on an oxidase test strip paper. All isolates that turned purple on the test strip paper after 10 seconds were suspected to be Staphylococcus species.

\subsection{Catalase Test}

Pure cultures of presumed Staphylococcus species from nutrient agar were aseptically transferred onto a clean glass slide. A few drops of $3 \% \mathrm{H}_{2} \mathrm{O} 2$ were then added to the cultures. Positive cultures of Staphylococcus species gave out bubbles of oxygen within 5 seconds of adding $\mathrm{H}_{2} \mathrm{O} 2$.

\subsection{API Staph Kit Test for Identification of Staphylococcus Species}

All presumed isolates were finally confirmed to their species level using the API staph kit (bioMerieux, France). Using the API Staph medium, homogeneous inoculums of pure cultured isolates were prepared with turbidity equivalent to $0.5 \mathrm{McF}$ arland. A pipette was used to fill the microtubes of the API kit with the inoculated API Staph medium. Mineral oil was added to the arginine DiHydrolase $(\mathrm{ADH})$ and urease (URE) tests to ensure anaerobiosis. The incubation box of the API kit was filled with $5 \mathrm{ml}$ of distilled water and closed tightly before incubating at $37^{\circ} \mathrm{C}$ for $24 \mathrm{hrs}$. After incubation, one drop of API Staph reagent was added to the inoculated microtubes to determine their reactions. The reactions of the inocula were read using the APIweb TM identification software (Biomerieux., Inc Quebec).

\subsection{Minimum Inhibitory Concentration (MIC) Determination}

Isolates identified to their species level were subjected to in-vitro drug sensitivity testing using the disc diffusion method as postulated by the Clinical and Laboratory Standards Institute (2015). Briefly, a few colonies of isolates were aseptically inoculated in normal saline to the desired turbidity (0.5 McFarland standards). With the aid of a sterile cotton swab, the inocula were evenly spread on Muller-Hinton agar in a petri dish plate. The antibiotic discs were then gently pressed on the agar and placed in an incubator for 24 hours at $37^{\circ} \mathrm{C}$. The MIC of each isolate was then determined by measuring (in millimeters) the zones of inhibition in the Mueller-Hinton agar with a meter rule to obtain the diameter of inhibition of the different isolates. Among the antibiotics used were Levofloxacin, Ciprofloxacin, Kanamycin, Meropenem, Ofloxacin, Tetracycline, Gentamicin, Erythromycin, Imipenem, Chlorofenicol, Nalidixic acid, Amoxicillin, Penicillin, Ampicillin, and Vancomycin.

\subsection{Statistical Analysis}

Data were analyzed using Microsoft Excel (2007) and SAS (2003). Descriptive statistics to generate percentage distribution was performed. A chi-square test $(\mathrm{p}<0.05)$ was employed to assess the association between the incidence of Staphylococcus species and risk factor variables, such as stage of lactation, parity number, and period of the year during the milk sample collection.

\section{RESULTS}

Of the 217 raw milk samples examined for bacterial growth, 13 different Staphylococcus species were isolated from $86(39.63 \%)$ positive samples. The distribution of Staphylococcus species is presented in Table 1. The most frequently isolated Staphylococcus species were Staphylococcus xylosus (22.09\%), Staphylococcus hominis (15.11\%), Staphylococcus haemolyticus (11.63\%), Staphylococcus sciuri (10.64\%), and Staphylococcus warneri (9.3\%). About $3.38 \%$ of the remaining species were due to Micrococcus spp. Of the 86 positive isolates bacterial species identified, the proportion of Staphylococcus species across the different sampling periods was $10 \%, 38 \%$, and $38 \%$, respectively (Table 
2). Of the 13 different Staphylococcus species isolated from milk samples, Staphylococcus xylosus (10\%, 10.52\%, and $36.84 \%)$, Staphylococcus epidermidis (10\%, 2.63\%, and 5.26\%), Staphylococcus haemolyticus (40\%, 5.26\%, and $10.65 \%)$, and Staphylococcus sciuri $(10 \%, 7.89 \%$, and $13.15 \%)$ were identified in each of the different sampling periods. There was a significant difference in the incidence of Staphylococcus species and some risk factors on the farm, including the period of milk sample collection and the stage of lactation at $\mathrm{p}<0.05$ Table 3.

Table 1. Proportion of Staphylococcus species isolated from 86 positive bovine milk samples.

\begin{tabular}{l|c}
\hline Staphylococcus species & Number (\%) \\
\hline S. epidermidis & $4(4.65)$ \\
\hline S. xylosus & $19(22.09)$ \\
\hline S. aureus & $3(3.48)$ \\
\hline S. haemolyticus & $10(11.63)$ \\
\hline S. hominis & $13(15.11)$ \\
\hline S. sciuri & $9(10.46)$ \\
\hline S. chromogenes & $5(5.81)$ \\
\hline S. warneri & $8(9.3)$ \\
\hline S. auricularis & $4(4.65)$ \\
\hline S. hyicus & $1(1.16)$ \\
\hline S. saprophyticus & $2(2.32)$ \\
\hline S. cohnii- cohnii & $3(3.48)$ \\
\hline S. cohnii- urealyticus & $2(2.32)$ \\
\hline Others & $3(3.48)$ \\
\hline Total & $86(100)$ \\
\hline
\end{tabular}

Table 2. Distribution of Staphylococcus species isolates identified from milk samples at different sampling periods of the year.

\begin{tabular}{l|c|c|c}
\hline Staphylococcus species & $\begin{array}{c}\mathbf{N}=\mathbf{7 6} \\
\text { Cold-dry (\%) }\end{array}$ & $\begin{array}{c}\mathbf{N}=\mathbf{8 1} \\
\text { Hot-wet (\%) }\end{array}$ & $\begin{array}{c}\mathbf{N}=\mathbf{6 0} \\
\text { Hot-dry (\%) }\end{array}$ \\
\hline S. epidermidis & $1(10)$ & $1(2.63)$ & $2(5.26)$ \\
\hline S. xylosus & $1(10)$ & $4(10.52)$ & $14(36.84)$ \\
\hline S. aureus & $2(20)$ & - & $1(2.63)$ \\
\hline S. haemolyticus & $4(40)$ & $2(5.26)$ & $4(10.52)$ \\
\hline S. hominis & $1(10)$ & $12(31.57)$ & - \\
\hline S. sciuri & $1(10)$ & $3(7.89)$ & $5(13.15)$ \\
\hline S. chromogenes & - & $3(7.89)$ & $2(5.26)$ \\
\hline S. warneri & - & $6(15.78)$ & $2(5.26)$ \\
\hline S. auricularis & - & $1(2.63)$ & - \\
\hline S. hyicus & - & - & - \\
\hline S. saprophyticus & - & - & $2(5.26)$ \\
\hline S. cohnii- cohnii & - & - & $3(6.97)$ \\
\hline S. cohnii- urealyticus & - & $2(5.26)$ & $2(5.26)$ \\
\hline Others & $10(100)$ & $38(100)$ & $3(2.63)$ \\
\hline Total & - & $38(100)$ \\
\hline Note: N represents total number of milk examined at each sampling period. & & \\
\hline
\end{tabular}

The antibiotic sensitivity test results for 78 isolates of CNS species against 15 different antibiotics are presented in Table 4. On the whole, the antimicrobial resistance test of the Staphylococcus species showed the highest rate of susceptibility against Levofloxacin (1.3\%), Imipenem (2.6\%), Ofloxacin (2.7\%), Gentamicin (5.1\%), Ciprofloxacin (5.1\%), Chlorofenicol (5.1\%), Meropenem (6.8\%), and Kanamycin (7.7\%). Whereas Staphylococcus species isolates showed the highest resistance to penicillin (83\%), Nalidixic acid (79\%), and Ampicillin (63\%). Considering individual Staphylococcus species, Staphylococcus cohnii-urealyticus was 100\% resistant to Erythromycin, Nalidixic acid, Imipenem, Vancomycin, Penicillin, and Ampicillin; Staphylococcus saprophyticus to Vancomycin, Penicillin, Amoxicillin, and Amoxicillin; and Staphylococcus cohnii-cohnii to Nalidixic acid, Penicillin, and Ampicillin.

\section{DISCUSSION}

From an aggregate of 217 milk samples collected throughout the three sampling periods, 86 (39.63\%) were positive for Staphylococcus species. Thirteen different Staphylococcus species were identified among the 86 isolates that tested positive. Staphylococcus xylosus (22.09\%), Staphylococcus hominis (15.11\%), Staphylococcus haemolyticus (11.63\%), and Staphylococcus sciuri $(10.46 \%)$ were the most frequently isolated species in this study. This result is somewhat in line with a study carried out in Canada (Davidson, Dohoo, Donald, Hariharan, \& Collins, 1992). Also, in the study by Kot et al. (2012), Staphylococcus xylosus was the most frequently isolated species. Farm management systems and farm surroundings may be a possible reason for our findings (Ayano et al., 2013; Bendahou, Lebbadi, Ennanei, Essadqui, \& Abid, 2008). Piessens et al. (2012) reported that a farm's environment may sometimes be a reservoir for Staphylococcus species. Some Staphylococcus species, including Staphylococcus xylosus, Staphylococcus hominis, and 
Staphylococcus haemolyticus, are known to be opportunistic and may find their way into the mammary glands of cows (Schukken et al., 2009). These Staphylococcus species have been reported to cause intra-mammary infections in cows (Quirk et al., 2012).

Table 3. Chi-square test for potential risk factors associated with the incidence of Staphylococcus species.

\begin{tabular}{|c|c|c|c|}
\hline Risk factor & Group & Number examined & P-value \\
\hline \multirow{4}{*}{ Parity } & First lactation & 25 & \multirow{4}{*}{0.9845} \\
\hline & Second lactation & 68 & \\
\hline & Third lactation & 57 & \\
\hline & Fourth lactation & 67 & \\
\hline \multirow{3}{*}{ Stage of lactation } & Early $(1-100)$ & 28 & \multirow{3}{*}{0.0039} \\
\hline & Mid (101-200) & 117 & \\
\hline & Late $(201<)$ & 72 & \\
\hline \multirow{3}{*}{ Sampling intervals } & Cold-dry & 76 & \multirow{3}{*}{0.0001} \\
\hline & Hot-wet & 81 & \\
\hline & Hot-dry & 60 & \\
\hline
\end{tabular}

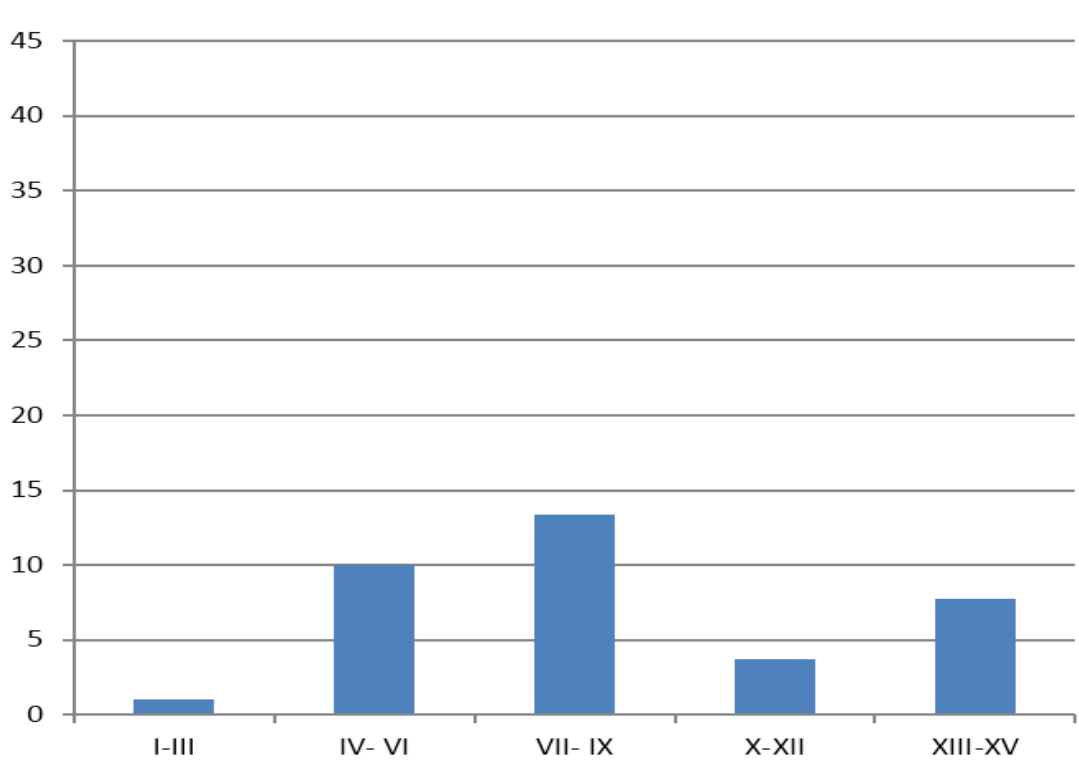

number of isolates

Figure 1. Distribution of multiple drug resistance to 15 antimicrobials drugs among 78 isolates of Staphylococcus species from bovine milk.

Note: I-III= Ciprofloxacin, Levofloxacin and Ofloxacin, IV-VI= Meropenem, Erythromycin and Nalidixic, VII-IX= Imipenem, Vancomycin and Penicillin, X-XII= Gentamicin, Tetracycline and Kanamycin, XIII-XV= Amoxicillin, Chlorofenicol and Ampicillin.

On account of the period of the year that the milk samples were collected, more Staphylococcus species (at the species level) were observed in the hot and dry period of the year compared with the other periods. The reason for this may be due to the adaptive ability and persistent nature of some Staphylococcus species to the mammary glands of cows (Piessens et al., 2012). In the current study, a particular Staphylococcus species was assumed to persist when isolated at least once in each sampling across the three different sampling periods. Thus, Staphylococcus epidermidis, Staphylococcus xylosus, Staphylococcus haemolyticus, and Staphylococcus sciuri were assumed to persist in cow udders. In another study by Taponen et al. (2007), Staphylococcus epidermis and Staphylococcus haemolyticus were also reported to persist in cow udders, but Staphylococcus xylosus was transient. Staphylococcus species (especially CNS) may differ in their degree of persistence (Taponen et al., 2007). Also, incidences of specific bacteria species vary along with the months of the year (Koivula et al., 2007).

In all, Staphylococcus xylosus and Staphylococcus hominis (22.09\% and $15.11 \%)$ were the most frequently isolated species observed in the study. They often occur as harmless organisms in human bodies and some parts of an animal's skin (Taponen, Björkroth, \& Pyörälä, 2008). However, they have been isolated from the milk of lactating cows (Kenar, Kuyucuoğlu, \& Şeker, 2012). The least isolated Staphylococcus species was Staphylococcus hyicus (1.16\%). This is different from the study carried out in Turkey, where Staphylococcus hyicus (33.33\%) was the most frequently isolated Staphylococcus species (Kirkan, Goksoy, \& Kaya, 2005). In another study carried out in Morocco, similar results to our study were observed (Bendahou et al., 2008). The variation in the frequency of isolation of these species may be a result of different study areas, which may have resulted from analysis of milk samples for bacteria growth before and after milk were collected from the farm (Koivula et al., 2007).

From the current finding, Staphylococcus cohnii-cohnii was the ninth-most frequently isolated Staphylococcus species. This result was similar to the study carried out by Kirkan et al. (2005).

Staphylococcus aureus is a major mastitis-causing pathogen on dairy farms. It was observed in this study to be the eighth-most (3.48\%) frequently isolated Staphylococcus species. The distributions of other Staphylococcus species include Staphylococcus warneri (9.3\%), Staphylococcus auricularis (4.65\%), Staphylococcus saprophyticus (2.32\%), and 
Staphylococcus cohnii-urealyticus (2.32\%). A few Staphylococcus species that were identified, including Staphylococcus warneri and Staphylococcus saprophyticus, may have resulted from contamination from the milking clusters used on the farm. These species were also isolated from the milking clusters and not from farmers' hands and may have been transferred from one cow to another from milk droplets in the milking clusters.

Not much work has been done on the incidence of CNS (at the species level) concerning the time of the year milk samples are collected (Gillespie, Headrick, Boonyayatra, \& Oliver, 2009). However, some studies have indicated that the time of the year influences the prevalence of mastitis-causing pathogens in milk (Gillespie et al., 2009; Osterås, Sølverød, \& Reksen, 2006). According to Koivula et al. (2007), Staphylococcus aureus was prevalent during the coldand-dry period of the year, more than any other period of the year. The reasons given for their findings were linked with cow's calving periods and farm management styles. Shpigel, Winkler, Ziv, and Saran (2000) reported that there was an increase in the incidence of mastitis caused by coliform bacteria in the wet-and-cold period of the year, but a lower incidence of coliform bacteria was observed in the hot-and-dry period. In another study in Norway, Staphylococcus aureus and Streptococcus uberis were prevalent in the hot-and-dry period of the year but, Streptococcus dysgalactiae and CNS (reported as a group) were more prevalent in the cold-and-dry period (Osterås et al., 2006). This may give a rational insight for a probable link in the time of milk sampling and the incidence of Staphylococcus species on farms (Gillespie et al., 2009).

More Staphylococcus species (at the species level) were isolated during the hot-and-dry period of the year in the current study. The numbers of species-specific isolates identified were 11, 10, and 6 during the hot-dry, hot-wet, and cold-dry periods, respectively. The difference in the results may be due to the variation in the climatic conditions (Piessens et al., 2012; Sampimon et al., 2011). The prevalence of mastitis-causing pathogens on a farm is linked to multiple complex factors, including environment, cowherd, the clinical state of the cow's udder, and the farm itself (Ayano et al., 2013; Supré et al., 2011; Thorberg, Danielsson-Tham, Emanuelson, \& Waller, 2009).

Some Staphylococcus species cause damage to the mammary of the cow udder rather than depending on their virulent attribute like others (Thorberg et al., 2009; Zhang \& Maddox, 2000). Their role to cause damage in mammary tissues of cows (mostly CNS) and to initiate a mastitis infection has not been plainly defined (Kirkan et al., 2005). However, relationships have been reported to exist between the stage of lactation and the incidence of Staphylococcus species (Abera, Demie, Aragaw, Regassa, \& Regassa, 2010; Taponen et al., 2007). Heifers and primiparous cows are known to be infected with mastitis by Staphylococcus species more often when compared with multiparous cows, though the reason for this is not yet clear (Taponen et al., 2007). There was no significant difference $(p=0.9845)$ in the incidence of Staphylococcus species and the number of lactating cows Table 3. A significant association was, however, observed for the incidence of Staphylococcus species in relation to the stage of lactation $(p=0.0039)$ and the period of year of milk sampling $(p=0.0001)$. Abera et al. (2010) also reported no significant difference in the incidence of Staphylococcus aureus and the number of lactations in cows but reported a significant association between the stage of lactation and the prevalence of Staphylococcus aureus in bovine milk. A lack of cleanliness of cow udders during dry periods was suggested by Abera et al. (2010) to influence the increase of bacteria on the skin of a cow's teat leading to possible high infection of bacteria in the udder.

Today, many farms are becoming dependent on antibiotics (Carter, Sun, \& Jump, 2016). The use of antimicrobials in dairy farms plays a significant role in controlling mastitis. Information about the variation that exists among speciesspecific Staphylococcus species is essential for mastitis therapy and management (Sawant et al., 2009). A large proportion of Staphylococcus species from this study were resistant to Erythromycin, Nalidixic acid, Vancomycin, Penicillin, Tetracycline, Amoxicillin, and Ampicillin (Table 4). There has been an increasing evolutionary trend of antibiotic resistance in infectious diseases in recent times (Davies \& Davies, 2010). This may be the reason for the observed result in the current study. One hundred percent resistant was observed by several Staphylococcus species isolates to Ampicillin in the current study (Table 4). This was contrary to Sawant et al. (2009), where most of the Staphylococcus species were susceptible to Ampicillin from their study.

In the study by Kot et al. (2012), high resistance to Penicillin was observed in Staphylococcus species. Penicillin and Ampicillin were the most commonly used antimicrobials on the farm where this study was conducted. However, from our results, Penicillin and Ampicillin may not be the proper choice treating Staphylococcus species. According to Kot et al. (2012), Staphylococcus species usually have high resistance against Penicillin and Ampicillin. The highest percentage of Staphylococcus species isolates that were resistant to Penicillin was Staphylococcus xylosus, Staphylococcus hominis, Staphylococcus warneri, Staphylococcus sciuri, and Staphylococcus haemolyticus, as presented in Table 4. All the isolates of Staphylococcus epidermidis displayed 100\% resistance to Penicillin (Table 4). This result is in accordance with Sampimon et al. (2011) and Kot et al. (2012), who reported that Penicillin resistance in Staphylococcus epidermidis was very high.

One hundred percent resistance was observed for Staphylococcus cohnii-urealyticus and Staphylococcus saprophyticus. Likewise, $100 \%$ resistance for six out of fifteen antimicrobial agents was observed for Staphylococcus cohniiurealyticus, while Staphylococcus saprophyticus gave resistance (100\%) to four out of fifteen antimicrobial agents used. Staphylococcus xylosus gave resistance $(10 \%, 10 \%, 5 \%, 70 \%, 65 \%, 80 \%, 90 \%, 5 \%, 10 \%, 15 \%, 66 \%$ and $88 \%)$ to Ciprofloxacin, Ofloxacin, Meropenem, Erythromycin, Nalidixic, Vancomycin, Penicillin, Gentamicin, Tetracycline, Kanamycin, Amoxicillin, and Ampicillin, respectively. The next Staphylococcus species with high resistance (9 out of 15) to multiple antimicrobial agents was Staphylococcus sciuri. 
Asian Journal of Agriculture and Rural Development, 12(1)2022: 10-19

Table 4. Distribution of resistant Staphylococcus species against different antibiotics.

\begin{tabular}{|c|c|c|c|c|c|c|c|c|c|c|c|c|c|c|c|c|}
\hline \multicolumn{17}{|c|}{ Number of antimicrobial resistant isolates (\%) } \\
\hline Staphylococcus spp & $\mathbf{N}$ & CIP & LEV & OFX & MEM & $\mathbf{E}$ & NAL & IMI & VA & PG & GM & $\mathbf{T}$ & $\mathbf{K}$ & AM & $\mathbf{C}$ & AP \\
\hline S. haemolyticus & 9 & 0 & $\mathrm{O}$ & 0 & 0 & $3(33)$ & $7(78)$ & $\mathrm{O}$ & $6(71)$ & $6(71)$ & 0 & $3(33)$ & 0 & $2(33)$ & 0 & $9(100)$ \\
\hline S. aureus & 3 & 0 & $\mathrm{O}$ & $\mathrm{O}$ & 0 & $1(33)$ & $2(67)$ & $1(33)$ & $2(67)$ & $2(67)$ & $2(67)$ & $1(33)$ & 0 & $\mathrm{O}$ & $\mathrm{O}$ & $3(100)$ \\
\hline S. sciuri & 7 & $2(29)$ & 0 & 0 & 0 & $4(57)$ & $7(100)$ & 0 & $4(57)$ & $5(71)$ & $1(14)$ & 0 & $3(43)$ & $\mathrm{O}$ & $3(43)$ & $6(86)$ \\
\hline S. hominis & 14 & 0 & $\mathrm{O}$ & $\mathrm{O}$ & 0 & 0 & $13(93)$ & 0 & $2(14)$ & $13(93)$ & 0 & $4(29)$ & 0 & $1(7)$ & 0 & NA \\
\hline S. epidermidis & 3 & 0 & $1(33)$ & $\mathrm{O}$ & 0 & $2(67)$ & $1(33)$ & 0 & $1(33)$ & $3(100)$ & 0 & $1(33)$ & 0 & $2(67)$ & 0 & NA \\
\hline S. xylosus & 20 & $2(10)$ & 0 & $2(10)$ & 5 & $14(70)$ & $13(65)$ & 0 & $16(80)$ & $18(90)$ & $1(5)$ & $2(10)$ & $3(15)$ & $13(66)$ & $\mathrm{O}$ & $18(90)$ \\
\hline S. auricularis & 4 & $\mathrm{O}$ & 0 & $\mathrm{O}$ & 0 & $\mathrm{O}$ & $3(75)$ & 0 & $\mathrm{O}$ & $3(75)$ & $\mathrm{O}$ & $2(50)$ & $\mathrm{O}$ & $1(25)$ & 0 & NA \\
\hline S. chromogenes & 4 & 0 & 0 & $\mathrm{O}$ & 0 & $1(25)$ & $3(75)$ & 0 & $1(25)$ & $3(75)$ & 0 & $1(25)$ & 0 & $1(25)$ & 0 & $\mathrm{O}$ \\
\hline S. warneri & 6 & 0 & 0 & 0 & 0 & $1(17)$ & $6(100)$ & 0 & $1(17)$ & $5(83)$ & 0 & 0 & $\mathrm{O}$ & 0 & 0 & $6(100)$ \\
\hline S. hyicus & 1 & 0 & 0 & 0 & 0 & $\mathrm{O}$ & $1(100)$ & 0 & 0 & 0 & 0 & $1(100)$ & $\mathrm{O}$ & 0 & 0 & $\mathrm{NA}$ \\
\hline S. cohnii- cohnii & 3 & 0 & 0 & 0 & 0 & $2(67)$ & $3(100)$ & 0 & $2(67)$ & $3(100)$ & 0 & $1(33)$ & $\mathrm{O}$ & 0 & 0 & $3(100)$ \\
\hline S. cohnii-urealyticus & 2 & 0 & 0 & 0 & 0 & $2(100)$ & $2(100)$ & $2(100)$ & $2(100)$ & $2(100)$ & $\mathrm{O}$ & $\mathrm{O}$ & 0 & $\mathrm{NA}$ & $1(50)$ & $2(100)$ \\
\hline S. saprophyticus & 2 & 0 & 0 & $\mathrm{O}$ & 0 & 0 & $1(50)$ & 0 & $2(100)$ & $2(100)$ & 0 & 0 & 0 & $2(100)$ & 0 & $2(100)$ \\
\hline Total & 78 & $4(5.1)$ & $1(1.3)$ & $2(2.7)$ & $5(6.4)$ & $30(39)$ & $62(79)$ & $2(2.6)$ & $39(50)$ & $65(83)$ & $4(5.1)$ & $16(21)$ & $6(7.7)$ & $22(28)$ & $4(5.1)$ & $49(63)$ \\
\hline
\end{tabular}

Note: NA: Not available. N: Number of isolates, CIP: Ciprofloxacin; LEV: Lev

Tetracyline; K: Kanamycin; AMO: Amoxicillin; C:Chlorofenicol; AP: Ampicillin. 
Staphylococcus aureus gave resistance to 8 (Erythromycin, Nalidixic acid, Imipenem, Vancomycin, Penicillin, Gentamicin, Tetracycline, and Ampicillin) out of the 15 antimicrobials, see Table 4. In Sweden, Persson, Nyman, and Grönlund-Andersson (2011) observed resistance by Staphylococcus aureus to Penicillin in their study, but not for Gentamicin and Erythromycin, which is in line with our observation. Staphylococcus aureus was susceptible to Chlorofenicol and Ciprofloxacin in our study and this is in line with the study carried out by Persson et al. (2011). All the Staphylococcus aureus isolates identified from this study were susceptible to Kanamycin. However, this was contrary to the report by Persson et al. (2011). The variation observed in the trend of Staphylococcus species against antimicrobial agents from this study may be a result of differences in virulence strains of the different species that were identified. According to Zhang and Maddox (2000), the difference in virulence strains of Staphylococcus species could lead to their differences in response to antimicrobial agents. The most susceptible Staphylococcus species (11 out of 15) to multiple antimicrobial agents was observed for Staphylococcus hyicus.

In regards to the number of isolates of Staphylococcus species that were resistant to multiple antimicrobial agents, 13 species were resistant to Imipenem, Vancomycin, and Penicillin. In comparison, ten isolates were resistant to Meropenem, Erythromycin, and Nalidixic acid (Figure 1). Conversely, four isolates of Staphylococcus species were resistant to Gentamicin, Tetracycline, and Kanamycin. This result is contrary to a study conducted in Argentina where all Staphylococcus species tested were susceptible to Gentamicin (Gentilini et al., 2002). The least number of isolates against multiple antimicrobial agents was observed for Ciprofloxacin, Levofloxacin, and Ofloxacin (Figure 1). The result of the huge multi-drug resistance witnessed on the farm may be due to the development of resistance by the Staphylococcus species prevalent to antimicrobial agents used for mastitis therapy. Frequent use of the same antimicrobial agents on a farm may lead to a transfer of resistant genes among mastitis-disease-causing organisms (Gentilini et al., 2002).

\section{CONCLUSIONS}

There was a relatively high incidence of Staphylococcus species with Staphylococcus xylosus, Staphylococcus hominis, and Staphylococcus haemolyticus identified from milk samples on the farm where this study was conducted. The stage of lactation and the period of the year during sample collection influenced the incidence of Staphylococcus species on the farm. A high rate of multiple drug resistance against antimicrobials agents was also observed on the farm, with Staphylococcus xylosus and Staphylococcus sciuri having the highest resistance against antimicrobial agents. The high resistance observed by most Staphylococcus species to multiple antimicrobial agents, including Penicillin and Ampicillin, which are frequently used on the farm, suggests that these drugs may not be effective against most of the Staphylococcus species for mastitis therapy control and hereby calls for a probable alternative antimicrobial agent to be used for the treatment of mastitis disease in cows.

Funding: This study received no specific financial support.
Competing Interests: The authors declare that they have no competing interests.
Authors' Contributions: Both authors contributed equally to the conception and design of the
study.
Views and opinions expressed in this study are those of the authors views; the Asian Journal of
Agriculture and Rural Development shall not be responsible or answerable for any loss, damage,
or liability, etc. caused in relation to/arising out of the use of the content.

\section{REFERENCES}

Abera, M., Demie, B., Aragaw, K., Regassa, F., \& Regassa, A. (2010). Isolation and identification of Staphylococcus aureus from bovine mastitic milk and their drug resistance patterns in Adama town, Ethiopia. Journal of Veterinary Medicine and Animal Health, 2(3), 29-34.

Ampe, B., Goethals, K., Laevens, H., \& Duchateau, L. (2012). Investigating clustering in interval-censored udder quarter infection times in dairy cows using a gamma frailty model. Preventive Veterinary Medicine, 106(3-4), 251-257. Available at: https://doi.org/10.1016/j.prevetmed.2012.04.004.

Ayano, A. A., Hiriko, F., Simyalew, A. M., \& Yohannes, A. (2013). Prevalence of subclinical mastitis in lactating cows in selected commercial dairy farms of Holeta district. Journal of Veterinary Medicine and Animal Health, 5(3), 67-72.

Batavani, R., Asri, S., \& Naebzadeh, H. (2007). The effect of subclinical mastitis on milk composition in dairy cows. Iranian Journal of Veterinary Research, 8(3), 205-211.

Bendahou, A., Lebbadi, M., Ennanei, L., Essadqui, F. Z., \& Abid, M. (2008). Characterization of Staphylococcus species isolated from raw milk and milk products (lben and jben) in North Morocco. The Journal of Infection in Developing Countries, 2(03), 218225. Available at: https://doi.org/10.3855/jidc.266.

Carter, R. R., Sun, J., \& Jump, R. L. P. (2016). A survey and analysis of the American public's perceptions and knowledge about antibiotic resistance. Open Forum Infectious Diseases, 3(3), 1-7.

Clinical and Laboratory Standards Institute. (2015). Performance standards for antimicrobial susceptibility testing. Paper presented at the 25th Informational Supplement. CLSI Document M100-S25, Clinical and Laboratory Standards Institute, Wayne, PA.

Davidson, T. J., Dohoo, I. R., Donald, A., Hariharan, H., \& Collins, K. (1992). A cohort study of coagulase negative staphylococcal mastitis in selected dairy herds in Prince Edward Island. Canadian Journal of Veterinary Research, 56(4), 275-280.

Davies, J., \& Davies, D. (2010). Origins and evolution of antibiotic resistance. Microbiology and Molecular Biology Reviews, 74(3), 417433.

Dufour, S., Dohoo, I., Barkema, H., DesCôteaux, L., DeVries, T., Reyher, K., \& Scholl, D. (2012). Manageable risk factors associated with the lactational incidence, elimination, and prevalence of Staphylococcus aureus intramammary infections in dairy cows. Journal of Dairy Science, 95(3), 1283-1300. Available at: https://doi.org/10.3168/jds.2011-4711. 
Gentilini, E., Denamiel, G., Betancor, A., Rebuelto, M., Fermepin, M. R., \& De Torres, R. (2002). Antimicrobial susceptibility of coagulase-negative staphylococci isolated from bovine mastitis in Argentina. Journal of Dairy Science, 85(8), 1913-1917. Available at: https://doi.org/10.3168/jds.s0022-0302(02)74267-7.

Gillespie, B., Headrick, S., Boonyayatra, S., \& Oliver, S. (2009). Prevalence and persistence of coagulase-negative Staphylococcus species in three dairy research herds. Veterinary Microbiology, 134(1-2), 65-72. Available at: https://doi.org/10.1016/j.vetmic.2008.09.007.

Gröhn, Y., Wilson, D. J., González, R., Hertl, J., Schulte, H., Bennett, G., \& Schukken, Y. (2004). Effect of pathogen-specific clinical mastitis on milk yield in dairy cows. Journal of Dairy Science, 87(10), 3358-3374. Available at: https://doi.org/10.3168/jds.s0022-0302(04)73472-4.

Halasa, T., Nielen, M., De Roos, A., Van Hoorne, R., De Jong, G., Lam, T., \& Hogeveen, H. (2009). Production loss due to new subclinical mastitis in Dutch dairy cows estimated with a test-day model. Journal of Dairy Science, 92(2), 599-606. Available at: https://doi.org/10.3168/jds.2008-1564.

Hogeveen, H., Huijps, K., \& Lam, T. (2011). Economic aspects of mastitis: Nnew developments. New Zealand Veterinary Journal, 59(1), 16-23. Available at: https://doi.org/10.1080/00480169.2011.547165.

Kenar, B., Kuyucuoğlu, Y., \& Şeker, E. (2012). Antibiotic susceptibility of coagulase-negative staphylococci isolated from bovine subclinical mastitis in Turkey. Pakistan Veterinary Journal, 32(3), 390-393.

Kirkan, B., Goksoy, E. O., \& Kaya, O. (2005). Identification and antimicrobial susceptibility of Staphylococcus aureus and coagulase negative staphylococci from bovine mastitis in the Aydın region of Turkey. Turkish Journal of Veterinary and Animal Sciences, 29(3), 791-796.

Koivula, M., Pitkälä, A., Pyörälä, S., \& Mäntysaari, E. A. (2007). Distribution of bacteria and seasonal and regional effects in a new database for mastitis pathogens in Finland. Acta Agriculturae Scand Section A, 57(2), 89-96. Available at: https://doi.org/10.1080/09064700701488941.

Kot, B., Piechota, M., Antos-Bielska, M., Zdunek, E., Wolska, K., Binek, T., \& Trafny, E. (2012). Antimicrobial resistance and genotypes of staphylococci from bovine milk and the cowshed environment. Polish Journal of Veterinary Sciences, 15(4), 741749. Available at: https://doi.org/10.2478/v10181-012-0113-4.

Osterås, O., Sølverød, L., \& Reksen, O. (2006). Milk culture results in a large Norwegian survey —effects of season, parity, days in milk, resistance, and clustering. Journal of Dairy Science, 89(3), 1010-1023. Available at https://doi.org/10.3168/jds.s0022-0302(06)72167-1.

Persson, Y., Nyman, A.-K. J., \& Grönlund-Andersson, U. (2011). Etiology and antimicrobial susceptibility of udder pathogens from cases of subclinical mastitis in dairy cows in Sweden. Acta Veterinaria Scandinavica, 53(1), 1-8. Available at: https://doi.org/10.1186/1751-0147-53-36.

Petzer, I.-M., Karzis, J., Watermeyer, J. C., Van der Schans, T. J., \& Van Reenen, R. (2009). Trends in udder health and emerging mastitogenic pathogens in South African dairy herds. Journal of the South African Veterinary Association, 80(1), 17-22. Available at: https://doi.org/10.4102/jsava.v80i1.163.

Piepers, S., De Meulemeester, L., de Kruif, A., Opsomer, G., Barkema, H. W., \& De Vliegher, S. (2007). Prevalence and distribution of mastitis pathogens in subclinically infected dairy cows in Flanders, Belgium. Journal of Dairy Research, 74(4), 478-483. Available at: https://doi.org/10.1017/s0022029907002841.

Piessens, V., De Vliegher, S., Verbist, B., Braem, G., Van Nuffel, A., De Vuyst, L., \& Van Coillie, E. (2012). Intra-species diversity and epidemiology varies among coagulase-negative Staphylococcus species causing bovine intramammary infections. Veterinary Microbiology, 155(1), 62-71. Available at: https://doi.org/10.1016/j.vetmic.2011.08.005.

Pitkälä, A., Haveri, M., Pyörälä, S., Myllys, V., \& Honkanen-Buzalski, T. (2004). Bovine mastitis in Finland 2001-prevalence, distribution of bacteria, and antimicrobial resistance. Journal of Dairy Science, 87(8), 2433-2441. Available at: https://doi.org/10.3168/jds.s0022-0302(04)73366-4.

Pyörälä, S., \& Taponen, S. (2009). Coagulase-negative staphylococci-emerging mastitis pathogens. Veterinary Microbiology, 134(12), 3-8. Available at: https://doi.org/10.1016/j.vetmic.2008.09.015.

Quirk, T., Fox, L., Hancock, D., Capper, J., Wenz, J., \& Park, J. (2012). Intramammary infections and teat canal colonization with coagulase-negative staphylococci after postmilking teat disinfection: Species-specific responses. Journal of Dairy Science, 95(4), 1906-1912. Available at: https://doi.org/10.3168/jds.2011-4898.

Sampimon, O., Lam, T., Mevius, D., Schukken, Y., \& Zadoks, R. (2011). Antimicrobial susceptibility of coagulase-negative staphylococci isolated from bovine milk samples. Veterinary Microbiology, 150(1-2), 173-179. Available at: https://doi.org/10.1016/j.vetmic.2011.01.017.

Sawant, A., Gillespie, B., \& Oliver, S. (2009). Antimicrobial susceptibility of coagulase-negative Staphylococcus species isolated from bovine milk. Veterinary Microbiology, 134(1-2), 73-81. Available at: https://doi.org/10.1016/j.vetmic.2008.09.006.

Sawant, A., Sordillo, L., \& Jayarao, B. (2005). A survey on antibiotic usage in dairy herds in Pennsylvania. Journal of Dairy Science, 88(8), 2991-2999. Available at: https://doi.org/10.3168/jds.s0022-0302(05)72979-9.

Schukken, Y. H., González, R. N., Tikofsky, L. L., Schulte, H. F., Santisteban, C. G., Welcome, F. L., \& Zadoks, R. N. (2009). CNS mastitis: Nothing to worry about? Veterinary Microbiology, 134(1-2), 9-14. Available at: https://doi.org/10.1016/j.vetmic.2008.09.014.

Shekhan, M., Al-Rodhan, M., \& AL-Janabi, J. K. (2011). Isolation and Identification of Staphylococcus spp. From Bovine Mastitic milk and their sensitivity to some Antibiotics at Al-Qadissiyah Province. Al-Qadisiyah Journal of Veterinary Medicine Sciences, 1O(2), 12-20. Available at: https://doi.org/10.29079/vol10iss2art150.

Shpigel, N., Winkler, M., Ziv, G., \& Saran, A. (2000). Clinical, bacteriological and epidemiological aspects of clinical mastitis in Israeli dairy herds. Preventive Veterinary Medicine, 35(1), 1-9.

Simojoki, H., Salomäki, T., Taponen, S., Iivanainen, A., \& Pyörälä, S. (2011). Innate immune response in experimentally induced bovine intramammary infection with Staphylococcus simulans and S. epidermidis. Veterinary Research, 42(1), 1-10. Available at: https://doi.org/10.1186/1297-9716-42-49.

Supré, K., Haesebrouck, F., Zadoks, R., Vaneechoutte, M., Piepers, S., \& De Vliegher, S. (2011). Some coagulase-negative Staphylococcus species affect udder health more than others. Journal of Dairy Science, 94(5), 2329-2340. Available at: https://doi.org/10.3168/jds.2010-3741.

Taponen, S., Björkroth, J., \& Pyörälä, S. (2008). Coagulase-negative staphylococci isolated from bovine extramammary sites and intramammary infections in a single dairy herd. Journal of Dairy Research, 75(4), 422-429. Available at: https://doi.org/10.1017/s0022029908003312. 
Taponen, S., Koort, J., Björkroth, J., Saloniemi, H., \& Pyörälä, S. (2007). Bovine intramammary infections caused by coagulasenegative staphylococci may persist throughout lactation according to amplified fragment length polymorphism-based analysis. Journal of Dairy Science, 90(7), 3301-3307. Available at: https://doi.org/10.3168/jds.2006-860.

Taponen, S., \& Pyörälä, S. (2009). Coagulase-negative staphylococci as cause of bovine mastitis-not so different from Staphylococcus aureus? Veterinary Microbiology, 134(1-2), 29-36. Available at: https://doi.org/10.1016/j.vetmic.2008.09.011.

Taponen, S., Simojoki, H., Haveri, M., Larsen, H. D., \& Pyörälä, S. (2006). Clinical characteristics and persistence of bovine mastitis caused by different species of coagulase-negative staphylococci identified with API or AFLP. Veterinary Microbiology, 115(13), 199-207. Available at: https://doi.org/10.1016/j.vetmic.2006.02.001.

Tenhagen, B.-A., Köster, G., Wallmann, J., \& Heuwieser, W. (2006). Prevalence of mastitis pathogens and their resistance against antimicrobial agents in dairy cows in Brandenburg, Germany. Journal of Dairy Science, 89(7), 2542-2551. Available at: https://doi.org/10.3168/jds.s0022-0302(06)72330-x.

Thorberg, B.-M., Danielsson-Tham, M.-L., Emanuelson, U., \& Waller, K. P. (2009). Bovine subclinical mastitis caused by different types of coagulase-negative staphylococci. Journal of Dairy Science, 92(10), 4962-4970. Available at: https://doi.org/10.3168/jds.2009-2184.

Waller, K. P., Aspán, A., Nyman, A., Persson, Y., \& Andersson, U. G. (2011). CNS species and antimicrobial resistance in clinical and subclinical bovine mastitis. Veterinary Microbiology, 152(1-2), 112-116. Available at https://doi.org/10.1016/j.vetmic.2011.04.006.

Walther, C., Rossano, A., Thomann, A., \& Perreten, V. (2008). Antibiotic resistance in Lactococcus species from bovine milk: Presence of a mutated multidrug transporter mdt (A) gene in susceptible Lactococcus garvieae strains. Veterinary Microbiology, 131(3-4), 348-357. Available at: https://doi.org/10.1016/j.vetmic.2008.03.008.

World Health Organization. (2000). Overcoming antimicrobial resistance. World Health Organization report on infectious disease 2000. Retrieved from http// www.who.int/infectious-disease-report/2000/index.html.

Zhang, S., \& Maddox, C. W. (2000). Cytotoxic activity of coagulase-negative staphylococci in bovine mastitis. Infection and Immunity, 68(3), 1102-1108. Available at: https://doi.org/10.1128/iai.68.3.1102-1108.2000. 